\title{
Angola um país de muitas faces: identidade e religiosidade
}

"A viagem não começa quando se percorrem distâncias, mas quando se atravessam as nossas fronteiras interiores" (Mia Couto).

Resumo: Utilizando a análise do discurso em Linha Francesa desenvolvida por Dominique Maingueneau, este artigo busca fazer uma análise da obra $O$ planalto e a estepe, de Pepetela, partindo da premissa de que a religiosidade angolana caracteriza-se como muitos olhares discursivos que se cruzam na narrativa. Nos fundamentaremos em Maingueneau (1997, 1998, 2002 e 2004) e Charaudeau (2004 e 2006), Chaves (2003), entre outros. Angola é um país com diferentes aspectos identitários e religiosos que influenciam questões sociais e históricas. O objetivo deste artigo é investigar como o discurso colabora para a construção religiosa na narrativa.

Palavras-chave: discurso, literatura angolana, religiosidade.

Abstract: Using the analysis of the French Line discourse developed by Dominique Maingueneau, this article seeks to make an analysis of Pepetela's The Plateau and the Steppe, starting from the premise that Angolan religiosity is characterized as many discursive looks that intersect in the narrative. We will base ourselves on Maingueneau (1997, 1998, 2002 and 2004) and Charaudeau (2004 and 2006), Chaves (2003), among others. Angola is a country with different identity and religious aspects that influence social and historical issues. The objective of this article is to investigate how the discourse collaborates for the religious construction in the narrative.

Keywords: speech, Mozambican literature, social denunciation.

\section{Introdução}

O romance $O$ planalto e a estepe, do escritor angolano Pepetela, caracteriza-se por uma narrativa com linguagem discursiva que envolve e convence o leitor quanto ao universo do período pós-colonial. Pode-se dizer que a narrativa é dividida em dois momentos: o primeiro diz respeito ao período colonial português que ficou marcado no imaginário, na cultura e modo de viver do povo. O segundo, período pós-colonial e pós-guerra.

A memória da palavra na narrativa do texto literário nos leva a refletir sobre as relações que ele evoca e sua contribuição para a construção identitária religiosa (individual, coletiva e nacional) em Angola, que se apresenta como uma nação que vive os reflexos do processo de descolonização. Uma nação híbrida, pois é formada pelas raízes africanas, pelas migrações dentro do próprio país e do continente, além das raízes europeias, que são retratadas

\footnotetext{
${ }^{1}$ Mestre em Língua Portuguesa pela Pontifícia Universidade católica de São Paulo e doutoranda em Língua Portuguesa na Pontifícia Universidade Católica de São Paulo. E-mail: mtbpadovani@gmail.com
} 
de forma poética na literatura, servindo de instrumento denunciador.

O país africano "vive uma realidade múltipla", pois Angola é a soma de uma nação fragmentada que se estrutura dentro de dois contextos históricos: o colonialismo e o período de emancipação territorial, marcado pela luta de libertação de Angola e de guerra civil. Por meio da literatura, o discurso literário de Pepetela de-

monstra em sua narrativa uma nação com grande diversidade cultural e social. Uma sociedade em que a religiosidade está presente nos diversos contextos históricos sociais. Entretanto, os povos nativos de Angola tiveram suas culturas e experiências religiosas negadas e proibidas durante muito tempo.

Assim, para entender o contexto atual de Angola, torna-se necessário compreender o contexto histórico passado e vivido pelo país, com várias nuances que marcaram o panorama nacional. Dessa forma, buscaremos, por meio da análise, entender o contexto cultural de Angola que após a independência do país registra adversidades culturais, políticas e econômicas e que são relatadas discursivamente na literatura como forma de protesto.

\section{Faces angolanas: língua, etnia, literatura, discurso multicultural}

Angola assumiu como língua de prestígio a língua portuguesa por ser uma língua que tinha representação comercial.

Para Lopes (2004, p. 240), a:

língua se relaciona com a sociedade porque é a expressão das necessidades humanas de se congregar socialmente, de construir e desenvolver o mundo. A língua não é somente a expressão da "alma" ou do "íntimo" do que quer que seja do indivíduo é, acima de tudo, a maneira pela qual a sociedade se expressa, como se seus membros fossem a sua "boca".

A língua é um patrimônio social, não pertence a um indivíduo apenas, mas a uma sociedade, a todos os usuários que irão usá-la conforme o interesse pessoal. Uma forma de expressão individual pode revelar expressões coletivas, pois mostra interesses em comum da sociedade. Dessa forma, a língua tem valor quando contextualizada em sociedade, quando é usada para os indivíduos interagirem uns com os outros. A língua é vista de forma abstrata pelos seus falantes, sendo comparada a elementos como fé, honra e outros.

Vale enfatizar então que, embora os falantes a vejam de forma abstrata, a língua serve aos usuários, refletindo seus anseios, sentimentos, emoções, ou seja, expressa as reações e manifestações do indivíduo, e em consequência disso, expressar a "identidade que se manifesta e se sustenta através da língua faz sentido" (LOPES, 2004, p. 241). Assim, a identidade de um indivíduo é a língua, transmitida entre gerações na interação social.

A identidade étnica é um conjunto de elementos como língua, cultura, costumes, religião, raça etc., pois não é uma única característica que constitui uma identidade, e sim um conjunto delas que determina se uma pessoa é ou não daquela sociedade-nação. Várias nações tiveram problemas com conflitos étnicos, em Angola não foi diferente. Os conflitos étnicos nas sociedades modernas têm relação com raça ou religião, ou melhor, geralmente usa-se a raça ou a religião para justificar os conflitos, porém, precisam ser analisados de forma profunda, a fim de perceber outros interesses que ficam camuflados como o político e o econômico. Além disso, "não podem ser explicados, exclusivamente, em relação aos valores da raça, cor, crença, língua ou da identidade étnica de um indivíduo. O que edifica ou destrói um homem (ou uma mulher) é a maneira como ele(a) vive ou é forçado (a) a viver" (LOPES, 2004, p. 242). 
Nos conflitos sociais sempre existiu o opressor e o oprimido, em lados opostos, o oprimido se submetendo à ideologia do opressor, que explora e domina segundo seus interesses. Assim também é o racismo, que explora e oprime, organizando-se conforme o interesse do opressor. Esse tipo de opressão está em todas as sociedades modernas. A obra de Pepetela mostra-nos como essas questões de opressor/oprimido e racismo estavam inseridas na sociedade angolana.

Em uma sociedade como Angola, a diversidade cultural permeia todos os ambientes sociais. Segundo Bechara (2011, p. 836), multiculturalismo consiste em "prática de acomodar culturas distintas, numa única sociedade, sem preconceito ou discriminação". O contexto angolano propicia a acomodação de culturas distintas, pois se tem em ambiente angolano a cultura do colonizador, a cultura do povo nativo e a cultura de outros povos que visitam o país para estudar, fazer negócios etc. Entretanto, Hall (2003) relata que o seu significado para alguns estudiosos da área não está bem enraizado ainda:

O termo "multiculturalismo" é hoje utilizado universalmente. Contudo, sua proliferação não contribuiu para estabilizar ou esclarecer seu significado. Assim como outros termos relacionados - por exemplo, "raça", etnicidade, identidade, diáspora — o multiculturalismo se encontra tão discursivamente enredado que só pode ser utilizado "sob rasura". Contudo, na falta de conceitos menos complexos que nos possibilitem refletir sobre o problema, não resta alternativa senão continuar utilizando e interrogando esse termo (HALL, 2003, p. 51).

As sociedades ou grupos multiculturais não são algo novo na história da humanidade. Pessoas, grupos e populações inteiras têm se deslocado ao longo dos séculos por vários motivos: natural, geográfico, colonial, escravidão, guerra civil, regime político. Segundo Hall (2003, p. 55) os impérios, entre eles, o império português (produto de conquista e dominação), são, geralmente, multiculturais. "Os impérios grego, romano, islâmico, otomano e europeu foram todos, de forma distinta, multiétnicos e multiculturais” (HALL, 2003:55). Em Angola, a diversidade linguística, decorrente da pluralidade étnica, contribui para exclusão e a desigualdade social. Para Lopes (2013, p. 07):

o conceito de multiculturalismo tem-se prestado a interpretações variadas [...] que enquadra o conceito num contexto contemporâneo e especifico, associando-o à noção de politica linguística. [...] o conceito de sociedade multicultural tem significado a manutenção de uma cultura dominante sobre as outras culturas, regra geral culturas das 'minorias', e a aceitação dessas mesmas culturas. Esta aceitação das outras culturas é, por outro lado, questionada, reivindicando-se um projecto cultural plural.

Angola é um país constituído por várias etnias e comunidades histórico-culturais, que interagem num rico e diversificado patrimônio cultural. Dessa forma, o multiculturalismo em Angola não deve levar a padrões culturais preestabelecidos, é importante procurar um equilíbrio entre os padrões culturais existentes na sociedade. Com isso, possibilita-se o contato e a compreensão de padrões culturais da minoria étnica que habitam o território nacional angolano.

Dessa forma, pensar em multiculturalismo é pensar sobre identidades plurais que executam as sociedades e que garantem a representação e valorização dessas identidades em espaços sociais. Sendo assim, o conceito de identidade é compreendido como composição, realizada nas diversas esferas sociais.

A produção literária é base comunicacional, possui uma função social, acompanhando as transformações socioeconômicas por que vão passando as sociedades, é por meio da 
produção literária que as expressões, significados e relatos se formam, possibilitando o aparecimento da literatura.

Segundo Chaves, a literatura foi:

Profundamente marcada pela História, a literatura dos países africanos de Língua Portuguesa traz a dimensão do passado como uma de suas matrizes de significado. A brusca ruptura no desenvolvimento cultural do continente africano, o contato com o mundo ocidental estabelecido sob a atmosfera de choque (2005, p. 45).

A literatura angolana reflete as ansiedades e manifestações do povo, mostrando a influência de antecedentes e fatos de caráter social, cultural e estético.

A literatura, porém, é coletiva, na medida em que requer uma certa comunhão de meios expressivos (a palavra, a imagem), e mobiliza afinidades profundas que congregam os homens de um lugar e de um momento, para chegar a uma 'comunicação' (CANDIDO, 2011, p. 147).

A tradição da oralidade é outro fator de influência na literatura angolana, revelando uma identidade cultural. Para Rita Chaves (1999, p. 65), o romance:

incorpora marcas do momento em que o desenvolvimento socioeconômico provoca fortes mudanças culturais, mexendo no cotidiano daquelas populações fixadas em torno de Luanda e das localidades próximas, situadas nas atuais províncias de Icolo e Bengo, Malange e Kuanza Norte.

Segundo Chatelain (apud ERVEDOSA, 1979, p.9-10), a literatura tradicional angolana é dividida em seis categorias:

A primeira são todas as histórias tradicionais de ficção, caracteriza-se pelo maravilhoso, tem como objetivo o entretenimento; a segunda são as histórias consideradas verdadeiras, objetivam instruir para futuras emergências; a terceira são as crônicas da tribo ou nação, relatam, geralmente, os segredos de estado, são guardadas e transmitidas pelos chefes e anciões de cada unidade politica; a quarta são os provérbios, as narrativas trazem questões da filosofia e da moral, algumas narrativas são explicações de provérbios; a quinta é a música e a poesia caracteriza-se pelo épico, bélico, dramático, satírico e religioso; a sexta e última é representada pelas adivinhas, são utilizadas para passatempo e divertimento.

Depois que Héli Chatelain categorizou a literatura angolana, outros passaram a estudar com mais afinco o tema. Em 1948, intelectuais angolanos - negros, brancos e mestiços lançaram, em Luanda, o brado "Vamos descobrir Angola", que tinha como objetivos romper com o tradicionalismo cultural imposto pelo colonialismo; debruçar-se sobre Angola e sua cultura, suas gentes e seus problemas; atentar para as aspirações populares, fortalecendo as relações entre literatura e sociedade; conhecer profundamente o mundo angolano de que eles faziam parte, mas que não figurara nos conteúdos escolares aos quais tiveram acesso.

Tal propósito fica claro nas palavras de Ervedosa (1974, p. 107), quando diz que "O vermelho revolucionário das papoilas dos trigais europeus encontraram-no, os poetas angolanos, nas pétalas de fogo das acácias, e a cantada singeleza das violetas, na humildade dos 'beijos-de-mulata' que crescem pelos baldios ao acaso". O autor destaca, ainda, que, "a metrópole portuguesa teve sempre a política de misturar as diferentes etnias para impedir a concentração de africanos de mesma origem numa mesma região”.

Sabe-se que a análise do discurso (AD) trouxe contribuições importantes para os 
estudos literários ao investigar as condições sociais de produção. Passa-se, então, à focalização de leitura como ato de (co)enunciação, visando ao caráter dialógico entre autor e leitor durante a construção de sentidos que a obra literária sugere.

Para Maingueneau (1996b, p. 5):

Todo enunciado, antes de ser esse fragmento de língua natural que o linguista procura analisar, é o produto de um acontecimento único, sua enunciação, que supõe um enunciador, um destinatário, um momento e um lugar particulares. Esse conjunto de elementos define a situação de enunciação.

Assim, o discurso literário revela-se ambíguo, pois, se de um lado reivindica um discurso verdadeiro, da pragmática, por outro é uma unidade estável, que possibilita o agrupamento de fenômenos que fazem parte de épocas e sociedades distantes e distintas entre si.

Para Charaudeau (1996, p.2):

A significação discursiva, pode-se afirmar, é uma resultante. Uma resultante de dois componentes dos quais um pode ser denominado linguístico, já que opera com material verbal (a língua), sendo ele mesmo estruturado de maneira significante segundo os princípios de pertinência que lhe são próprios e outro, situacional, já que opera um material psicossocial, testemunha dos comportamentos humanos, que colabora na definição dos seres ao mesmo tempo como atores sociais e como sujeitos comunicantes.

A propósito dessas afirmações, fazer parte do campo literário não significa "ausência de todo lugar, mas, como dissemos uma negociação entre lugar e não lugar, um pertencimento parasitário que se alimenta de sua inclusão impossível” (MAINGUENEAU, 2006, p.92). Nesse sentido, o romance de Pepetela deve ser estudado visando às relações sociais estabelecidas no contexto angolano e, por meio do discurso histórico-social, no qual são definidos contratos comunicativos. Segundo Maingueneau (1995, p.122):

Suporte de um ato de discurso socialmente reconhecido, a obra é enunciada através de uma instituição, no caso, um gênero de discurso determinado que ele próprio, num nível superior, mobiliza essa vasta instituição que é a literatura. As condições de enunciação vinculadas a cada gênero correspondem a outras tantas expectativas do público e antecipações possíveis dessas expectativas pelo autor.

A literatura é capaz de estabelecer e antecipar relações entre língua, linguagem, história, sociedade e vida, possibilitando um jogo dialético, em que o sujeito revela a interioridade de sua essência, procurando compreender-se e se situar no mundo, busca entender a sua relação com os outros, sua relação com o mundo. A literatura, possibilita a compreensão da humanidade, e como ocorreram fatos históricos em um dado momento. Assim, uma análise da linguagem não pode ignorar a literatura, pois ela faz parte da construção da língua.

De fato, existe uma relação essencial entre a construção da identidade de uma língua e a existência de uma literatura, de um corpus de enunciados estabilizados e valorizados esteticamente: a produção de enunciados de qualidade dá qualidade de língua (MAINGUENEAU, 2010, p.29).

Com a literatura, é possível, por meio de um jogo dialético, que o homem busque interiorizar-se com o meio social, com sua essência e com o mundo. Na literatura, "a língua coloca à disposição de cada um múltiplo repertório de possibilidades” (PROENÇA, 2001, 


\section{p.23).}

Dessa forma, podemos dizer que o texto literário é ao mesmo tempo, estético e linguístico, pois na literatura depreendemos as duas categorias, entretanto, a literatura é o objeto da linguagem que revela questões ideológicas e sociais.

A matéria literária é cultural. O artista da palavra retira do mundo elementos que, conveniente-

mente organizados, podem representar totalidades e constituir uma afirmação cuja força e coesão não se encontram ao alcance dos profanos. (PROENÇA, 2001, p. 33).

Só há literatura onde existe povo. Pepetela permite-nos situar os diferentes domínios entre linguagem, língua e discurso cultural do povo angolano e suas características. Os dêiticos discursivos possibilita a identificação do "aqui" e do "agora" em contexto angolano. Os dêiticos são elementos linguísticos que indicam o lugar "aqui” ou o tempo "agora" em que um enunciado é produzido e também indicam os participantes de uma situação do enunciado (eu/tu). Ilari e Geraldi (2006, p.66) destacam que:

os dêiticos realizam o fenômeno da dêixis (ato de mostrar), que é um dos traços que distinguem a linguagem humana das linguagens artificiais, tornando-a apropriada para uso em situações correntes, o termo 'dêixis' significa 'apontar para'.

É válido destacar que as formas dêiticas funcionam como elementos fundamentais no processo de contextualização. Esses elementos apontam referência a um objeto ou a um signo do mundo real representado no texto. Segundo Guimarães (2009, p. 80):

Para interpretar essas formas numa mostra de discurso, é necessário saber quem são o falante e o ouvinte (dêixis pessoal), bem como o espaço (dêixis espacial) e o tempo (dêixis temporal) de produção do discurso - dependendo, então, o sentido do discurso das circunstâncias da enunciação. (grifos do autor)

Os dêiticos classificam-se em:

Dêixis pessoal - os pronomes pessoais - indicam as pessoas do discurso, os participantes, permitindo selecioná-los na interação comunicativa. Integram este grupo: os pronomes pessoais (eu, tu, ele, nós, vós, eles, me etc.), determinantes e pronomes possessivos (meu, nosso, vosso, teu etc.), sufixos flexionais de pessoa-número (falas, falamos etc.), bem como os vocativos.

Dêixis espacial- assinala os elementos espaciais, tendo como ponto de referência o lugar em que decorre a enunciação, ou seja, evidencia a relação de maior ou menor proximidade ao lugar ocupado pelo locutor. Cumprem esta função os advérbios ou locuções adverbiais de lugar, que também são marcadores de tempo (aqui, cá, além, acolá, perto, lá de cima etc.); os determinantes e os demonstrativos (este, esse, aquele, aquilo, outro, mesma etc.), bem como alguns verbos que indicam movimento (ir, chegar, aproximar-se, afastar-se, entrar, sair, subir, descer etc.). Além disso, os dêiticos só podem ser entendidos se houver uma explicitação, dentro da situação de comunicação. Por exemplo, uma mensagem como: Eu quero que você vá hoje ao cinema. O termo "hoje" perde o sentido, se não houver um referencial de data. E ainda, o pronome pessoal "eu" deve aparecer, explícito no contexto, caso contrário, ninguém sabe a quem o texto se refere.

Dêixis temporal - localiza, no tempo, um fato tomando como ponto de referência o "agora" da enunciação. Desempenham esta função os advérbios, locuções adverbiais ou expressões de tempo (amanhã, ontem, na semana passada, no dia seguinte etc.) e sufixos flexionais de tempomodo-aspecto (falarei, falávamos, faláveis etc.).

Dêixis social - assinala a relação hierárquica existente entre os participantes da interação 
discursiva e os papéis por eles assumidos. Servem de suporte a essa função os elementos linguísticos pertencentes às chamadas formas de tratamento (senhor, senhora etc.).

Os dêiticos inserem-se em diversas categorias gramaticais, adquirindo sentido pleno apenas no contexto em que se incluem. Assim, pertencem à categoria dos dêiticos:

os pronomes pessoais; os pronomes e determinantes possessivos; os pronomes e determinantes demonstrativos; os artigos; os advérbios de lugar e de tempo; os tempos verbais; alguns vocábulos, como "ir/vir" (movimento de afastamento/aproximação em relação ao espaço em que se encontra o locutor e o interlocutor, respectivamente).

É importante destacar, ainda, que os dêiticos discursivos em nosso trabalho caracterizam-se como palavras que apontam a situação em que o discurso foi materializado, auxiliando para que haja o conhecimento partilhado em interação comunicativa dos co - enunciadores.

\section{O romance: uma análise discursiva de $O$ planalto e a estepe}

Passaremos a analisar a obra "O planalto e a estepe", à luz da Análise do Discurso de Linha Francesa (AD), destacando a religiosidade por meio dos dêiticos de acordo com Maingueneau (2007). Cabe-nos traçar um paralelo entre o período colonial em que Júlio, (personagem principal na obra) viveu a infância, e o período de combate para independência de Angola, período em que o personagem participou como integrante/combatente e comandante.

Sendo assim, a obra literária aponta que a identidade caracteriza-se pela religiosidade de Júlio, educado dentro dos preceitos do catolicismo, tanto em sua família quanto no colégio em que estudava. Na obra, o discurso religioso ideológico, que no caso de Angola, reflete a ideologia e a identidade do colonizador português. No espaço angolano colonial, o mundo real é camuflado, substituído por um mundo imaginário:

Falei com padre Mateus, o qual coçou minha cabeça, na obrigação de ajudar uma ovelha ${ }^{2}$ do seu rebanho mais tresmalhada do que nunca. Não lhe saiu nenhuma ideia válida, apenas me aconselhou a rezar muito e a arrepender-me dos numerosos pecados. (PEPETELA, 2009, p. 21).

O meu professor de Filosofia era outro padre. [...] Quero falar da inteligência e das ideias. Cedo se mostrou um professor diferente dos outros. [...] Um dia disse, quero ensinar-vos a pensar. [...] E lhe perguntei com todo o descaramento o que aqueles homenzarrões eram e o que diziam. Quanto a bolchevique, era simples explicar, os comunistas russos assim se chamavam e ele até me podia explicar porque mais tarde, mas importante agora era isso de ser amigo ou não dos pretos e insistiu, Jesus Cristo disse para sermos todos irmãos e eu fazia muito bem em ser amigo de todos, não havia nisso pecado, antes pelo contrário, pecadores eram os que diziam só os pretos podem ser amigos dos brancos, não o inverso. Esses são racistas e são colonialistas. (PEPETELA, 2009, p. 23).

A religião católica foi imposta no território angolano colonial pelos portugueses, caracterizada como ideal para a nação e superior à religião local. Nos trechos destacados,

\footnotetext{
2 A ovelha do rebanho revela-nos o discurso de dominação religiosa, pois, teoricamente, ovelha é um animal frágil que precisa ser conduzido. No caso do locutor Júlio, o padre tinha que conduzi-lo para que fugisse dos pensamentos revolucionários, ou seja, aceitasse a posição de dominado. A boa ovelha segue as pegadas do por pastor, assim, o locutor discursivo não obra de Pepetela não era uma boa ovelha.
}

https://periodicos.unifap.br/index.php/letras Macapá, v. 8, n. 3, $2^{\circ}$ sem., 2018 
podemos verificar que os dêiticos mencionam as diferentes pessoas do discurso. No primeiro trecho, temos o verbo "falei" e o pronome pessoal oblíquo "me" marcam o discurso questionador do locutor ao padre Mateus (autoridade da igreja) sobre a forma como foi abordado por homens do governo Salazar. Já o verbo (dêitico) "coçou" e o pronome pessoal oblíquo "lhe" referem-se ao padre e à sua reação perante o questionamento de Júlio. $\mathrm{O}$ discurso do padre Mateus revela manifestações sociais e de identidade, que retomam o discurso colonizador.

No segundo trecho, o pronome possessivo "meu” demonstra certa aproximação entre o professor e Júlio, a relação de pertencimento aos mesmos preceitos católicos. "Eu" (dêitico e pronome pessoal do caso reto) tem a função de caracterizar o pertencimento de Júlio à identidade religiosa revelada pelo padre indiano. "Aqueles" (dêitico e pronome demonstrativo) e "os que diziam" dizem respeito aos seguidores do governo Salazar que representa a voz do colonizador, apontando para o distanciamento, para a rejeição. O padre indiano representa o discurso de unificação angolana de libertação, o discurso de dominação sociopolítica.

Assim, o discurso religioso racista ora funciona como conciliador pelo padre Mateus, ora como libertador pelo padre indiano. Enquanto o padre Mateus dizia que andar com negros era pecado, o padre indiano dizia que quem não queria que brancos e pretos ficassem juntos era colonialista e racista. Logo em seguida, o locutor informa ao leitor o destino que o padre indiano teve pela igreja: "obrigaram-no a partir para o Vaticano e por lá ficar a envelhecer e fazendo estudos de Teologia. Até se perder e esquecer que havia vida no universo. [...] Os homens bons duravam pouco na nossa terra." (PEPETELA, 2009, p. 24). As convicções ideológicas do padre indiano não atendiam às convicções colonialistas, por isso, foi retirado do convívio da sociedade angolana.

No colégio, Júlio entrava em contato com o modelo ideológico de ensino de Portugal e com os padres que ministravam as aulas. Assim, o colégio também funcionava como referência religiosa ideológica para os estudantes. Depois de realizar as transgressões como: pegar dinheiro da mãe sem permissão para comprar cigarros e fumar escondido, Júlio ia se confessar com os padres que sempre mandavam rezar três Ave Marias e três Pais Nossos. Ainda na adolescência e no relato de memória sobre sua construção identitária, Júlio é obrigado pela família a frequentar o catecismo do Padre Mateus. Não fica contente com os ensinamentos dos religiosos e acaba fazendo críticas aos rituais do catolicismo; como no trecho a seguir.

Mas era difícil chegar ao Paraíso. Pelo menos o padre Mateus não facilitava. Todos estávamos devidamente condenados ao Inferno, pecadores que éramos. Quanto mais nos esforçávamos, mais nos enterrávamos no Inferno, vãos eram os gestos e as rezas. Mesmo depois da comunhão e de todas as confissões. Comparávamos as confissões de uns e outros, entre nós não havia segredos. As confissões eram todas iguais. Iguais também os castigos. Três Ave-Marias e dois Padre-Nossos, ou o inverso, tanto fazia, ia dar tudo à inutilidade, ao Inferno. (PEPETELA, 2009, p. 17).

Ao criticar a ideologia católica, herança ancestralmente ligada à alma lusitana, Júlio se aproxima da cultura dos da terra e de seus companheiros nas aulas de catecismo, os filhos de Kanina.

Em outro trecho, podemos verificar o discurso religioso de oposição entre os católicos e as religiões nativas, ou seja, a diversidade religiosa em território angolano e a concepção identitária angolana: 
Os feiticeiros do Congo eram fortes e meu amigo devia ser um deles. Adivinhou o meu destino claro. Hoje sei de qualquer forma não foi este gesto infantil que forçou o meu destino, ele há muito estava escrito, esse destino adivinhado por qualquer feiticeiro do Congo. (PEPETELA, 2009, p.88)

No trecho em destaque, o substantivo (dêitico) "os feiticeiros" faz alusão às crenças religiosas dos ancestrais angolanos, o pronome pessoal 'deles' retoma os feiticeiros ancestrais. Os dêiticos "meu amigo" e "ele" fazem referência a Kanina, amigo negro de Júlio. Pode-se dizer que Júlio transitava entre os dois mundos religiosos: o imposto por Portugal e o das origens de seu povo. É importante destacar que a busca de identidade, inclusive religiosa, é marca da personalidade de Júlio em todo o discurso narrativo:

A dado momento, acharam-me capaz de comandar um pequeno grupo de homens. Sempre evitei admitir essa capacidade, ela me aterrorizava. Havia alguns tabus no meu espírito para me manter são na guerra. Um, já vimos, era o de nunca considerar a presença próxima de familiares ou amigos do outro lado da barricada; outro, fugir à promoção a cargos que exigissem comando. Tive de aceitar o posto, na guerra se aprende a regra da obediência. No entanto, e para meu terror, em breve me apercebi da razão de uma certa falta de confiança no grupo: os homens tinham passado por cerimónias rituais para blindarem o corpo às balas inimigas. No entanto, se o seu comandante não estivesse blindado, de pouco lhes valeriam as suas proteções, ficavam contaminados pela fraqueza do chefe. Tais dúvidas levavam-nos a muitas hesitações na altura de executarem as minhas ordens e a arranjarem sempre desculpas para evitar certos riscos ou apenas incomodidades, tais como marchas nocturnas. Já me tinham advertido desse perigo, sobretudo o comissário político o destacamento, hábil na manipulação das vontades e crenças, para isso era comissário. (PEPETELA, 2009, p. 121-122).

Ao observarmos o enunciado acima, podemos verificar que ele nos apresenta como elementos dêiticos os pronomes pessoais oblíquos "me", "se", caracterizando o locutor discursivo. Num primeiro momento, mostra a relação hierárquica dentro do MPLA e o jogo discursivo político. Em contexto de guerra, não há culpados ou inocentes, as fronteiras entre o bem e o mal são tênues e deslizam de um grupo para outro conforme os interesses em questão. Diante desse contexto, as identidades individuais no jogo discursivo de guerra são nulas, pois prevalecem os interesses do coletivo.

Como em toda guerra, existem aqueles que são comandantes e aqueles que são comandados, os empoderados e os descapacitados. O pronome pessoal do caso oblíquo "lhe" refere-se aos soldados, enquanto o pronome pessoal "nos" sugere o comandante e os soldados em uma mesma situação comunicativa. Convém destacar ainda que, neste trecho, a religiosidade dos angolanos se torna importante dentro do contexto colonial de libertação, pois são elementos presentes na identidade, memória e discurso do colonizado/soldado do MPLA. O fenômeno religioso é utilizado para justificar a participação dos angolanos nativos nos movimentos de guerrilha, interferindo, inclusive, na hierarquia do grupo, já que os soldados não querem ir para a batalha por acreditarem que seu comandante não tem corpo blindado, colocando todos em risco.

_Entrei na cubata e estava muito escuro, só um fraco fulgor vinha do chão onde ardeu uma pequena fogueira e agora só tinha brasas. Vocês sabem como é uma cubata onde morre uma fogueira. Mal via o camarada que me servia de intérprete e entrou comigo na cubata. Este falou para alguém agachado no chão, junto ao braseiro, um vulto encolhido. Já íamos preparados e entregamos a galinha, isto é, o galo, um galo preto. O quimbanda, um homem velho e mirrado, de barba branca, se levantou então com alguma dificuldade e pegou no galo, sem uma palavra amarrou $[. .$.$] .$

https://periodicos.unifap.br/index.php/letras

Macapá, v. 8, n. 3, $2^{\circ}$ sem., 2018 
Tinha prendido a atenção dos meus companheiros. Todos me fixavam, imóveis. Só o branco dos olhos deles surgia na espessura da noite, onde se escondem todos os mistérios. [...].

- Ordenei então ao meu companheiro para disparar sobre mim, que se lixasse se a vida de um quimbunda fosse um aldrabão [...]

- O galo, nas minhas costas, parou de estrebuchar, depois de duas sacudidelas. Eu passei a mão pelo peito mas não senti sangue. O quimbanda foi por trás de mim e cortou o cordel. O galo caiu no chão, morto. Eu estava vivo. E com blindagem da melhor que há. Aqui, bala vira água, não entra - afirmei, pomposo, batendo no peito. (PEPETELA, 2009, p. 122, 123, 124, 125).

Ainda sobre o discurso religioso e sua representação para os africanos/angolanos, o trecho acima, apresenta-nos uma cerimônia de "blindagem" do corpo para a guerra. Com relação aos elementos dêiticos, podemos afirmar que eles fazem referência a pessoas diferentes no discurso. Os verbos "entrei”, “ordenei”, "passei”, "senti”, "afirmei” e os pronomes pessoais "me" e, "mim", mencionam o locutor e comandante de uma tropa de soldados relatando como passou pela blindagem do corpo aos homens do pelotão.

Já o pronome demonstrativo "este" faz menção ao intérprete, que, neste caso, é um intérprete dos costumes e das crenças locais, acompanha o comandante. O pronome indefinido invariável "alguém" pressupõe uma pessoa indefinida no contexto enunciativo; pela cena enunciativa subentende-se que se trata de um benzedeiro, ou a pessoa responsável em realizar o ritual.

O verbo no pretérito imperfeito do indicativo "íamos", engloba na enunciação o comandante Júlio Pereira e o intérprete que o acompanhava. O pronome indefinido "todos" e o pronome possessivo "deles" anunciam os soldados que ouviam o relato do comandante.

É válido destacar que a crença em qualquer localidade do mundo, não é um elemento isolado da sociedade, desenvolve-se em um contexto social e plural, econômico e cultural. No caso em questão, a blindagem do corpo do comandante, mesmo ele contando um fato que não aconteceu, pois o general não participou realmente da cerimônia de "blindagem", os homens do pelotão acreditaram no discurso rico em detalhes, pois o general era conhecedor das crenças locais. A religião serviu como instrumento social e cultural de identidade naquele contexto, deslocado para instrumento de poder nas mãos de Júlio, que passou a ser respeitado pelos homens que comandava.

Ao analisar o trecho mencionado, podemos destacar que usando a mais poderosa das armas, a fé, assim como os colonizadores portugueses fizeram ao implantar o projeto de colonizar Angola, Júlio o fez, porém, em uma vertente religiosa contrária à dos colonizadores, que impuseram o catolicismo. Júlio, conhecedor do território angolano, mostrou aos soldados que era um homem da terra, que era igual a eles, que acreditava nas crenças angolanas.

Destacamos, ainda, que a relação entre memória discursiva e identidade mostra-se importante na obra em questão. É nas interações sociais que as identidades são construídas; sempre a partir de um conjunto de diálogos estabelecidos em situações é que afloram sentimentos e emoções de pertencimento e de visões do mundo. Com isso, a divisão, no contexto discursivo de guerra, o "aqui" enunciado por "eu", convida à comunhão, o discurso é manifestado, e, em certa medida, partilhado.

A memória de um povo é muito importante na construção da identidade de uma sociedade. Na obra, essa relação é estabelecida por meio dos personagens, que demonstram o passado distante por meio da memória e buscam um presente melhor. O passado representa o período colonial, o período da escravidão dos angolanos pelos portugueses, e da exploração comercial. Os personagens buscam na memória fatos que podem identificá-los com 
o presente.

\section{Conclusão}

A análise da obra de Pepetela, O planalto e a estepe, apontou que a identidade religiosa é representada por meio dos personagens. O romance apresenta Angola com um cruzamento entre identidades culturais, que se entrecruzam nos discursos do cotidiano. Mostrando que as culturas angolanas e portuguesas devem se relacionar, sem que uma se imponha com relação à outra, como aconteceu no passado, possibilitando que as culturas não percam sua identidade.

Além disso, o romance leva ao leitor ao mundo imaginário para demonstrar que a religião católica, que representa a identidade portuguesa convive diariamente com as crenças locais. É importante dizer ainda que conforme afirmam Signorini e Tevês em Angola ocorre o que podemos chamar de heterogeneidade entre culturas, pois podemos perceber que a cultura portuguesa e a moçambicana estão presentes na esfera social moçambicana, através da interação social as culturas são transmitidas e se entrecruzam.

\section{Referências}

CANDIDO, Antonio. Literatura e subdesenvolvimento. A Educaşão pela noite e outros ensaios. São Paulo, Ática, 1992.

CHARAUDEAU, P. Para uma Nova Análise do Discurso. In: CARNEIRO, A.D. (Org.) O Discurso da Mídia. Rio de Janeiro: Oficina do autor, 1996.

CHARAUDEAU, Patrick e MAINGUENEAU, Dominique. Dicionário de análise do discurso. coordenação da tradução Fabiana Komesu. São Paulo: Contexto, 2004.

CHAUÍ, Marilena. O que é ideologia. Coleção Primeiros Passos. São Paulo. Editora Brasiliense. Publicação original, 1980. Publicação digital, 2004.

CHAVES, Rita. Angola e Moçambique - experiência colonial e territórios literários. Cotia, SP: Ateliê Editorial, 2005.

CHAVES, R. A formação do romance angolano: entre intenção e gestos. São Paulo, Universidade de São Paulo: Via Atlântica, 1999.

- José Luandino Vieira: consciência nacional e desassossego. Revista de Letras/Fundação Editora UNESP, vol. 40. Assis: 2000.

CHAVES, R.; MACEDO Tânia (orgs). Portanto...Pepetela. São Paulo: Ateliê Editorial, 2009. COLOMER, T. A formação do leitor literário: narrativa infantil e juvenil atual. São Paulo: Global, 2005.

Ervedosa, Carlos (1979), Roteiro da Literatura Angolana. Luanda: UEA.

GUIMARÃES, Elisa. Texto, discurso e ensino. São Paulo: Contexto, 2009.

HALL, Stuart. $A$ identidade cultural na pós-modernidade. $11^{\mathrm{a}}$ ed., Rio de Janeiro, RJ: DP\&A, 2006.

HALL, Stuart. "Quem precisa de identidade?” In: SILVA, T.T. (org.), HALL, S., WOODWARD, K. Identidade e diferença: A perspectiva dos estudos culturais. Petrópolis: Vozes, 2000. p.103-133.

ILARI, Rodolfo; GERALDI, João Wanderley. Semântica. 11ª ed. São Paulo: Ática, 2006.

MAINGUENEAU, Dominique. Termos chave da análise do discurso. Uberlândia: Editora UFMG. 2006. . O contexto da obra literária. 1a. ed. São Paulo : Martins Fontes, 1995. 
1996b.

Pragmática para o Discurso Literário. São Paulo: Martins Fontes, 1996a. . Elementos de Linguistica para o Texto Literário. São Paulo: Martins Fontes,

Novas tendências em Análise do Discurso. 3 ed. Campinas SP: Pontes:

Editora da Universidade Estadual de Campinas, 1997. - Análise de textos de comunicação. São Paulo: Cortez, 2002.

ORDONEZ, S. Introducción a La semântica funcional. Madrid: Síntesis, 1992.

PEPETELA. O planalto e a estepe. São Paulo: Leya, 2009.

PROENÇA, Domício Filho. A linguagem Literária. São Paulo, SP: Editora Ática, 2001. 